\title{
Cofradías en Torrelaguna (Madrid)
}

\section{INTRODUCCIÓN *}

La investigación se ha desarrollado en Torrelaguna, comunidad perteneciente a la comarca Somosierra-Lozoya de la provincia de Madrid, a $58 \mathrm{Kms}$. de la capital. Está situada a orillas del río Jarama, no lejos de su confluencia con el Lozoya y hasta hace pocos años fue partido judicial. Actualmente tiene 2.481 habitantes, población que se viene manteniendo bastante estática desde 1900 en que tenía 2.380 .

Su economía está basada en agricultura de secano - principalmente cultivo de cereales-, algo de regadío y poca ganadería. Antaño, el cultivo de la vid adquirió cierta relevancia. La importancia del Canal de Isabel II ha sido considerable desde su creación, transformando, en parte, las condiciones de vida de sus habitantes al ofrecerles una alternativa laboral, con lo que las economías familiares han evolucionado desde lo agrícola a un carácter mixto de subsistencia.

Los datos han sido recogidos en un tiempo de algo más de seis meses, visitando la comunidad dos o tres veces por semana ${ }^{1}$. Los que se aportan en el artículo se han obtenido tanto del trabajo de campo realizado mediante observación participante, entrevistas, material fotográfico, etc., como de los libros y documentos parroquiales y de las propias hermandades estudiadas.

Debemos manifestar, por último, que el trabajo reviste ciertos visos de provisionalidad, deseando continuar en el futuro esta investigación con el fin de comprobar de facto la exactitud de nuestras conclusiones,

* Queremos agradecer especialmente a Mariano Cid Sánchez la inestimable ayuda prestada en el curso de la investigación y sin la cual hubiera sido algo menos que imposible la realización del estudio.

1 El trabajo de campo se llevó a cabo durante el año 1982. El artículo se presentó a las I Jomadas de Antropología Social de Castilla-León, celebradas en Avila en noviembre de 1982, cuyas Actas no se han publicado. 
y que se presenta con una concepción de uniformidad en sus líneas básicas respecto a otras investigaciones llevadas a cabo por el equipo de trabajo del Museo Nacional de Etnología y la Asociación Madrileña de Antropología.

En función de los datos de campo obtenidos, vamos a manejar dos hipótesis:

1. ${ }^{a} \quad$ La existencia de dos tipos de hermandades en la comunidad de Torrelaguna: unas de tipo grupal y otra de carácter comunal o patronal con la salvedad de que esta última cumplió funciones grupales que, en la actualidad, se manifiestan en un nivel simbólico.

$2 .^{a}$ Se dan dos niveles de identificación sociocultural en la comunidad: el nivel parroquial para las hermandades grupales y otro patronal que incluye a toda la comunidad en sus correspondientes tiempos de expresión ritual.

Para el desarrollo de estas hipótesis hemos tomado como referencia el modelo tipológico propuesto por Isidoro Moreno en su libro Las Hermandades andaluzas ${ }^{2}$ y en un artículo posterior ${ }^{3}$.

Con respecto a las hermandades de tipo grupal, tipológicamente verticales y abiertas - tres hermandades: San Isidro, San Sebastián y Santa Bárbara - ${ }^{4}$ corresponden a las denominadas hermandades de socorro y ayuda mutua o, como dice Isidoro Moreno «organizaciones religiosobenéficas con importantes funciones mutuales especialmente referidas a

2 Véase Isidoro MoReno, Las Hermandades andaluzas (Sevilla: Universidad de Sevilla, 1974), pp. 30 y ss.

3 Isidoro MORENO, «Cofradías andaluzas y fiestas: aspectos socioantropológicos», Honorio M. Velasco (ed.), Tiempo de fiesta (Madrid: Ed. Trescatorcediecisiete, 1982), pp. $73-93$

4 La Hermandad de San Isidro se fundó en 1694, sus ordenanzas son de 1703 y posteriormente ratificadas por el cardenal Portocarrero. La de San Sebastián se creó en 1793, siendo sus ordenanzas de 1801 y ratificadas por el Consejo de Toledo en 1815. No hay datos de la fecha de fundación de la de Santa Bárbara; la única referencia histórica se encuentra en las ordenanzas de San Sebastián en las que se dice que son las mismas que las de Santa Bárbara. El culto a la Soledad como tal, el viaje a la ermita, etc., parece ser de origen franciscano. El Cardenal Cisneros impuso, cuando donó al convento franciscano de Torrelaguna la ermita de Santa María de la Cabeza, la obligación de celebrar una procesión hasta la ermita de la Virgen de Malacuera -que es la que hoy corresponde a la Virgen de la Soledad- el día del nacimiento de Nuestra Señora, día de la fiesta de Torrelaguna. La advocación de la Virgen de la Soledad no existía realmente; fue en 1750 , más o menos, cuando este culto tomó auge, reparándose la ermita y celebrando procesiones, con una importante donación de bienes hecha por un presbítero del pueblo expresamente a la Virgen de la Soledad. 
las prácticas funerarias: velatorio, enterramiento, etc., corriendo a cargo de los hermanos y pagadas a expensas de la hermandad» ${ }^{5}$. Este tipo de hermandades parece ser característico de Castilla, incluso en la actualidad; mientras que en la Baja Andalucía las hermandades de socorro están prácticamente extinguidas ${ }^{6}$. En efecto, los datos, tanto históricos como de campo, confirman el carácter religioso benéfico de las tres hermandades mencionadas. Así, tanto las de San Sebastián y San Isidro, como la de Santa Bárbara, expresan en sus reglas los fines básicos de la hermandad: el culto al santo y la asistencia social a los hermanos enfermos y acompañamiento fúnebre de los hermanos fallecidos. Esta asistencia social y acompañamiento funerario generaba rituales mortuorios con gran riqueza de elementos: hachas, estandartes, cetros, velas, misas y funerales, etc. Asimismo, existía como característica común de sancionamiento y control social por parte de las hermandades, el cargo de listero, para controlar la asistencia de los hermanos en sus obligaciones de entierro y velatorio. La no asistencia a dichos actos era sancionada con el pago de una multa que, de no ser satisfecha, podía suponer la expulsión de la hermandad.

En la actualidad, estas funciones de socorro y ayuda han quedado reducidas al pago de una cantidad estipulada - cada hermandad tiene asignada una diferente- como aportación para sufragar gastos de entierro. En esta diferencia en el dinero aportado para el entierro es donde se manifiesta de hecho el carácter diferencial entre las distintas hermandades, según los fines y funciones desempeñadas. Mientras que en Santa Bárbara y San Isidro la ayuda para el entierro -el acompañamiento ritual como expresión simbólica de la pertenencia a una determinada hermandad $y$, en nuestro caso, a un determinado estrato socioeconómico-cultural no se lleva a cabo desde hace muchos años- sigue siendo una de las funciones principales de la hermandad; en San Sebastián se pretende, sin embargo, "potenciar la fiesta del santo con un espíritu de fiesta y confraternización, más que el de cofradía de socorro $\mathrm{y}$ asistencia».

En cuanto a la cofradía de la Virgen de la Soledad, que celebra su fiesta el 8 de septiembre y que por cierto no es la patrona oficial del pueblo, pero sí la patrona devocional del mismo, se puede decir que expresa la identidad colectiva de toda la comunidad, absorbiendo la grupalidad de las otras tres hermandades grupales; pero esto ya lo veremos más adelante en la expresión ritual.

\footnotetext{
5 Op. cit., 1974, p. 41.

6 Ibid., p. 41.
} 
Una vez mostrado el carácter de «ayuda mutua, socorro y enterramiento" de estas hermandades, pasamos a describir las características restantes tanto de las grupales como de la comunal. Estas tres hermandades responden al criterio de grupal, desde el momento que representan una cierta identidad de un grupo social, aparte de la vinculación común en el culto a un santo determinado. Tradicionalmente, a San Sebastián pertenece el barrio del Arrabal, barrio extramuros en el que vivían los jornaleros y actualmente los obreros ${ }^{7}$. A San Isidro pertenecen los labradores, y en relación a Santa Bárbara se dio una identificación de la clase media compuesta principalmente por comerciantes, así como de la clase alta, y en los años cincuenta un fuerte contingente de los trabajadores del Canal de Isabel II ${ }^{8}$.

La verticalidad de las tres hermandades se sostiene con la presencia de todos los estratos sociales en los segmentos grupales correspondientes. Así, en San Isidro, tanto pertenecen los labradores fuertes con propiedades extensas como los pequeños propietarios, lo mismo que en Santa Bárbara y en San Sebastián. El carácter abierto viene expresado en que no hay un número fijo de hermanos, ya que se pueden adscribir quienes y cuantos quieran.

A la vista de lo expuesto, pudiera parecer que las hermandades aludidas responden a un modelo de segmentación social en tres estratos, al menos, con el consiguiente carácter horizontal que implica la identidad y pertenencia grupal de dichos estamentos sociales hacia las hermandades respectivas.

7 Isidoro MORENo, op. cit., 1974, pp. 44 y ss., habla de las hermandades de barrio como producto evolutivo de las hermandades étnicas y gremiales que, en su debilitamiento, se transforman de una hermandad basada en la ocupación - hermandad gremial- a otra basada en la residencia - hermandad de barrio-. En nuestro caso, la hermandad de San Sebastián no responde a esta descripción en tanto que su identidad se manifiesta por la oposición intra-extra muros: el Arrabal frente a la villa amurallada. Asimismo, los censos consultados a partir de 1915 demuestran que el Arrabal estaba habitado en su mayor parte por jornaleros.

8 Respecto al origen y vinculación de los santos específicos de cada organización, hemos recogido la tradición oral que se refiere a San Sebastián, al cual se le consigna en una doble vertiente: una, presenta al santo como kun izquierdista que se enfrentaba desde el Arrabal a la clase rica, que lo persiguió, prendió y flechó. Los del Arrabal le hicieron una ermita y las tierras que poseía pasaron a manos de la hermandad [constituida], que desde entonces los administra». Otra, lo presenta como «un bailarín que actuaba para ricos y reyes. Tenía que ser algo masoquista porque decían que disfrutaba cuando lo apedreaban, y cuando lo flecharon en un árbol camino de La Cabrera, se reía». 
Podemos afirmar que en el caso de San Isidro sí se dio el carácter horizontal de la hermandad, ya que en sus reglas fundacionales se limitaba el acceso a los demás sectores sociales que no fueran labradores.

Por otra parte, el carácter de estas cofradías sí podía responder, antaño, a un modelo horizontal, en tanto la adscripción a las mismas se basaba en la identificación social con cada una de las hermandades. Existió, además, durante mucho tiempo la norma restrictiva de no poder pertenecer a más de una hermandad, independientemente de la patronal ${ }^{9}$. Si se daba la identificación grupal y no se podía pertenecer a más de una de estas hermandades, parece obvio que los criterios de pertenencia y adscripción apuntaban hacia: $1 .^{\circ}$, un acceso basado en una identificación social exclusivista de pertenencia, y $2 .^{\circ}$, una estructuración triádica que subsumía la estructura social en una hermandad de culto comunal -aunque, como veremos más adelante, cumplía funciones grupales de enterramiento-, en la cual se integraban aglutinadas (en el sentido de que las hermandades diluyen su propia identidad grupal ante el culto comunal) las tres hermandades grupales. Es decir, mientras que en las celebraciones rituales de las hermandades de San Isidro, San Sebastián y Santa Bárbara aparecía todo el aparato formal y simbólico de su estructura como expresión de su grupalidad, en la de la Soledad esta segmentación no aparecía representada sino a un nivel simbólico en el que precisamente no existen conflictos. Se produce lo que Isidoro Moreno denomina «negación simbólica de la realidad social» ${ }^{10}$, haciéndose evidente la configuración comunal-vertical-abierta del culto patronal, en nuestro caso la Virgen de la Soledad, cuya verticalidad aparece también en la adscripción y acceso, pudiendo pertenecer a la hermandad todo aquel que lo desee, sin distinción de clase, sexo o edad. Precisamente es la hermandad que más adeptos y hermanos tiene; la cuota anual de 25 pesetas permite a todo el pueblo pertenecer a ella.

Ahora bien, en la actualidad sólo parte de lo anteriormente expuesto parece ser cierto, pues con el paso del tiempo y desde principios de siglo, en estas hermandades se ha diluido el carácter externamente horizontal, carácter expresado más en criterios de pertenencia que de reglamentación exclusivista, convirtiéndose éste en una posterior manifestación, más o menos cotidiana, de las oposiciones inter-hermandades, pero

9 La adscripción se hacía, y se hace, por filiación, aunque se da el caso de que muchas personas se adscriben por matrimonio, cuando lo habitual es que, cónyuges de distinto origen social pertenezcan a diferentes hermandades. Hoy existe una fuerte tendencia a las dobles y triples adscripciones.

10 Op. cit., 1974, p. 29. 
permitiendo que su estructura acogiera a personas de distintos estamentos sociales sin diferenciación ${ }^{11}$.

\section{APARATO FORMAL}

Habiendo ya señalado el carácter de enterramiento en la hermandades, es preciso reseñar algunos datos del aparato formal, sobre todo de las actividades anuales, jerarquía y modos de financiación.

Tradicionalmente la actividad anual de las hermandades se reducía a su función o fiesta, que no tenía por qué coincidir con el día del santo patrono, como ocurre de hecho en las de San Sebastián y Santa Bárbara ${ }^{12}$. La primera la celebra el primer sábado y domingo del mes de mayo, y la segunda, el sábado y domingo posterior a San Isidro, única hermandad que mantiene la fiesta en su día.

Hasta años muy recientes las hermandades estaban regidas por una Junta Directiva compuesta por un abad, dos alcaldes, dos mayordomos y dos sacristanes, que se elegían por riguroso orden de antigüedad. Luego había una serie de oficios como el de celador, encargado de llevar el orden de vela a los hermanos enfermos, el de listero, los gavilladores, et Asimismo, nos encontramos con un secretario y un depositario de los fondos de la hermandad, elegidos por la Junta y a los que se pagaba. Los cargo; de la hermandad se elegían por un año y esta elección tenía lugar el día de la fiesta del santo. Ellos eran los encargados de organizar las diferentes actividades y de llevar el control de la hermandad ${ }^{13}$.

Actualmente esto ha cambiado, ya que nadie quiere hacerse cargo de estos asuntos. Por ejemplo, en la hermandad de San Sebastián en el año 1980 se eligieron democráticamente un alcalde-presidente, un alcalde-secretario y un alcalde-tesorero con un mandato de dos años que son los que están llevando a cabo la tarea de revitalizar la hermandad. En San Isidro sucede lo mismo, mientras que en Santa Bárbara conti-

11 Los únicos criterios de discriminación establecidos en las hermandades son las disposiciones y acuerdos llevados a cabo, tanto en juntas anuales como por intervención eclesiástica, de no permitir la ostentación de cargos directivos a las mujeres. Así se expresa en la ordenanza 22 de las hermandades de San Sebastián y Santa Bárbara, y en las Providencias del año 1787 de la hermandad de San Isidro.

12 La hermandad de San Sebastián celebraba el día del santo patrono con una misa en la ermita y una chocolatada que se daba después al cura-abad y a la Junta Directiva.

1.3 En los días siguientes a la fiesta se reunían las Juntas Directivas - la entrante y la saliente - para aprobar las cuentas de esta última. Comían en casa del alcalde durante seis días hasta la liquidación de dichas cuentas. 
núan en los cargos, desde hace bastantes años, los tres hermanos más antiguos.

Las hermandades se financian con las cuotas o derramas que pagan los hermanos. El dinero obtenido por la subasta de varas y rosquillas, que se lleva a cabo los dos días que dura la fiesta, es otra fuente de financiación ${ }^{14}$.

El número de miembros de estas hermandades varía de una a otra, así, Santa Bárbara es la más numerosa: en 1982 tenía 720 hermanos; San Isidro alrededor de 470, y San Sebastián, de 200 que tenía en 1980, ha pasado a más de 400 en la actualidad.

En cuanto a la hermandad comunal, la de la Virgen de la Soledad, debemos señalar el fuerte resurgimiento a partir de 1939, cuando el culto se reinicia bajo el control no sólo parroquial, sino también obispal, ya que el obispo sancionaba positiva o negativamente a la persona propuesta por el cura párroco para su admisión. Lo más significativo de su aparato formal está en la configuración de la jerarquía: en los estatutos propuestos en 1951 por el párroco - los libros desaparecieron durante la guerra civil- se hace mención de la Junta Directiva, compuesta por el párroco (presidente de honor), presidente, secretario y un tesorero, aduciendo que el presidente efectivo podrá ser designado por el cura párroco, así como el secretario y el tesorero. El control eclesiástico parece, según esto, absoluto. Durante todo este tiempo la hermandad funcionó con un presidente -el último secretario que tuvo ésta lo fue antes de la guerra- que asumía las funciones de alcalde y administrador, con el asesoramiento de otra persona que ejercía de secretario y notario. El resto de las personas que componen la Junta, la camarera mayor, etc., eran personas de cierta alcurnia que con sus donativos ayudaban a mantener el culto. Sin embargo, cuando murió este último presidente, y debido a un intento por parte de la iglesia de controlar de nuevo la hermandad, ésta actuó unilateralmente eligiendo al actual presidente, persona de características sociales insignes y de prestigio en el pueblo, así como al resto de la Junta Directiva.

14 Otras fuentes de ingreso en el pasado eran las multas impuestas a los hermanos que no asistían a las diversas actividades organizadas por la hermandad - léase entierros, misas, etc.- y la salida de insignias y estandartes en entierros de los hermanos fallecidos, por lo que se cobraba un canon establecido a las familias que lo pidiesen. Además, San Sebastián recibe, incluso hoy, unas cantidades por el arrendamiento de una tierra de labor, era y casa del ermitaño, que salen a subasta pública entre los hermanos cada cuatro años. Es el único caso de propiedades por parte de una hermandad, ya que las restantes no tienen ninguna. 
La Junta se debe reunir una vez al año para aprobar las cuentas y tratar los asuntos de las novenas y procesiones de la fiesta. Su funcionamiento es autónomo y permanente, ya que los cargos, al ser propuestos por su significación social, no se someten a plazos definidos. Pese a ello, la Junta queda encargada de mantener el culto de la imagen, siendo considerada en un nivel emic por el pueblo como entidad administrativa que rige el funcionamiento del culto y ritual, estando la propia devoción y culto por encima de esta estructura jerárquica. Esto vendría a caracterizar a la Junta Directiva como exponente máximo del prestigio social, estrictamente hablando.

La función de los hermanos no aparece delimitada sino que solamente lo son de número. No se hace uso del sistema de asamblea de hermanos, sino que los dirigentes de la hermandad seleccionan, si ha lugar, a los cargos.

Es actividad de la hermandad organizar la novena y la procesión de Semana Santa, cuando se traslada la imagen al pueblo donde permanece durante 15 días.

En cuanto a las funciones grupales que la hermandad lleva a cabo, hasta 1935 sufragaba los gastos de entierro a sus hermanos, portando símbolos y estandartes en el acompañamiento. Es decir, esta hermandad se situaba en el mismo plano de las funciones de enterramiento que las otras, asumiendo, además, las funciones comunales en la época de fiestas. Actualmente estas funciones de carácter grupal se expresan con la contribución simbólica de quinientas pesetas para ayuda al entierro, sin llevar a cabo el acompañamiento de difuntos. Por otra parte, esta ayuda no es solicitada por ninguno de los hermanos, convirtiéndose, de alguna manera, en donativos implícitos.

La financiación, el mantenimiento del culto y de las fiestas religiosas se obtiene a través de las derramas, pujas de las andas - en 1982 se pujó por meter la carroza- y numerosos donativos que la Virgen recibe y que administra la hermandad.

La hermandad de la Virgen de la Soledad es la más numerosa de todo el pueblo, como parece lógico. Tiene algo más de 800 hermanos nominales, siendo las mujeres las que protagonizan en su mayor parte los cultos religiosos con la asistencia a la novena.

\section{EXPRESIÓN RITUAL}

A continuación presentamos los datos de campo acerca de la expresión ritual de la actividad anual más importante de las hermandades, 
es decir, la fiesta. A través de su estudio podremos apreciar en su conjunto el mapa de la estructura social que en nuestro caso vendrá explicado por tres hermandades grupales y otra comunal que las integra.

En la fiesta las tres hermandades siguen un esquema básico de vísperas con procesión y luminaria, y el día de la fiesta con misa, refresco y procesión. Tradicionalmente celebraban el mismo ritual, pero hoy día existen algunas variaciones en él. La fiesta se inicia con las vísperas que comienzan por la tarde con la procesión del santo patrono, conducido desde la ermita, donde está todo el año, a la iglesia parroquial. Ahora bien, la única hermandad que tiene ermita propia es la de San Sebastián; Santa Bárbara está alojada en la ermita de Nuestra Señora de la Soledad, y San Isidro en la parroquia.

En la fiesta de San Sebastián la procesión se inicia a media tarde, siendo sacado el santo de la ermita por mujeres, sin que haya anteriormente ningún oficio religioso y sin que asista el párroco revestido, ya que sólo le acompaña a título particular; lo mismo sucederá en la procesión de las otras dos hermandades. No está determinado quiénes son los encargados de sacarlo, aunque se ofrece a las personas que pujaron el año anterior para meterlo. Primero va la banda de música, detrás el cetro - llevado, en 1982, por un muchacho cuya familia pujó el año anterior por él, a pesar de ser una de las más marginadas de la hermandad, siendo el cetro un signo de prestigio-. Detrás de éste sale el estandarte, portado por una mujer, y por último la imagen del santo. La comitiva no guarda ningún orden, delante van las hermanas, que asisten en mayoría, y al final se sitúan los pocos hermanos asistentes que van hablando y gastando bromas. El alcalde-presidente no está situado en lugar determinado, sino que recorre la procesión vigilando su desarrollo e iniciando los vivas al santo que serán coreados por el resto de la comitiva.

El recorrido es largo, por fuera de las originarias murallas; durante el trayecto se hacen paradas para que se agregue más gente y asimismo se lanzan gran cantidad de cohetes. La procesión pasará por lo que en Torrelaguna se conoce como la Puerta del Sol, un lugar donde es mayor la concurrencia y donde se efectúa un mayor control social. Aquí arreciarán los vivas al santo y se lanzarán más cantidad de cohetes, mientras que el público observador comenta la grandiosidad y lucimiento de la procesión.

Una vez que se ha llegado a la puerta de la iglesia parroquial, repican las campanas para dar la bienvenida ${ }^{15}$, se coloca al santo de cara

15 En San Sebastián repicarán más y con más fuerza porque el campanero es un 
al público y comienza la subasta de las varas, pues quien pague más por ellas tendrá el derecho de «entrar al santo» en la iglesia. Una vez acabada esta subasta comenzará la de las rosquillas. Finalizadas ambas se procede a meter al santo, que se coloca en el altar mayor, quedando allí hasta el día siguiente.

En 1982, la hermandad de San Isidro no celebró la procesión de vísperas, sólo la del día de la fiesta, que fue por la tarde y salió de la parroquia para luego volver a ella. Abriendo paso iba un cetro portado por un niño, detrás otro cetro, luego la banda de música y por fin las tres imágenes que lleva la procesión: un San Isidro pequeño, portado por niños, un San Isidro grande que se turnan para llevar hermanos y hermanas, y Santa María de la Cabeza, llevada exclusivamente por mujeres. La procesión es bastante concurrida y sin guardar mucho orden; el recorrido es largo y pasa también por la Puerta del Sol. Al llegar más o menos a la mitad del camino la procesión se divide: los dos San Isidros siguen su marcha por la calle que conduce a una de las arterias principales y Santa María de la Cabeza se desvía por un callejón, llamado de Santa María de la Cabeza o «de las mujeres», siendo acompañada sólo por las mujeres. Después de un pequeño rodeo, se llega de nuevo a la calle principal, donde en realidad no se produce un «encuentro", pues no hay parada; simplemente la santa se coloca en su puesto anterior. El cortejo recorre la parte suroeste del pueblo, sin tocar el barrio del Arrabal, volviendo a la Puerta del Sol y de allí a la iglesia donde al llegar los santos se tocan las campanas y se inicia la subasta de varas y rosquillas. Éstas no alcanzaron precios tan altos como en San Sebastián.

Santa Bárbara también celebra la procesión de vísperas, que sale de la ermita de la Virgen de la Soledad. Delante van los músicos, detrás el cetro, que es llevado por una mujer, y a continuación la santa, llevada también por mujeres. El tono general del cortejo, a diferencia de San Sebastián y San Isidro, es mucho más formal, más respetuoso y casi más devoto. Sólo los hermanos, al final, hablan y se gastan bromas entre ellos. El itinerario transcurre por la carretera para unirse al mismo de las otras: pasar por la Puerta del Sol para acabar en la iglesia parroquial, donde se producirá el toque de campanas, como sucede con las otras hermandades, y la subasta de varas y rosquillas ${ }^{16}$.

miembro de la hermandad. Sin embargo, no rechazamos la hipótesis de que antaño cada hermandad tuviera una señal sonora identificadora y propia.

16 Es importante resaltar el decisivo papel de las mujeres, no sólo en el funcionamiento interno de las hermandades - en la Virgen de la Soledad son mujeres las que 
El año en que se realizó esta investigación los hermanos de Santa Bárbara tuvieron un altercado con los de San Isidro que estaban terminando su procesión. Esto sucedió al tener Santa Bárbara que cambiar la fecha de su fiesta, que tradicionalmente se celebra el sábado y domingo posterior a San Isidro, debido a que ese año, por esas fechas, estaban programadas las comuniones y una visita del obispo. Se pasó la fiesta al sábado y domingo anteriores, coincidiendo la celebración de la víspera con el día de San Isidro. Ante esta contingencia, se pusieron de acuerdo las dos hermandades con el fin de poder compartir así el gasto de la música y de la luminaria. Se celebraría antes la procesión de San Isidro, debiendo terminar a una hora fijada para que, a continuación, se pudiese celebrar la subasta de Santa Bárbara ante la iglesia. Pero no sucedió así: la de San Isidro se retrasó con la subasta y la de Santa Bárbara tuvo que esperar, por lo que los primeros fueron conminados por los otros a concluir para poder empezar ellos con la suya. Así, lo que había empezado con un acuerdo acabó con un enfrentamiento y sensación de usurpación del día - por parte de los de San Isidro-, y con la de un acuerdo no cumplido - por parte de los de Santa Bárbara-. La culpa pareció recaer sobre el párroco quien aseguró que se terminaría el acto de San Isidro a la hora convenida.

En el pasado se hacía la luminaria por la noche; cada hermano tenía la obligación de aportar una gavilla de leña, siendo los gavilladores los encargados de recogerlas por las casas y llevarlas a la plaza donde se hacía el fuego. Este año sólo en la fiesta de San Sebastián se llevó a cabo este ritual, que no sólo incluye la lumbre, sino la celebración de un «sarao» o baile en la plaza para todo el pueblo. El acuerdo entre Santa Bárbara y San Isidro de celebrar conjuntamente la luminaria sin lumbre, se vio frustrado al llover esa noche, siendo motivo de burla por parte de los de San Sebastián.

Al día siguiente se inicia la fiesta con misa en la parroquia, tanto para San Sebastián como para el resto, dando lugar posteriormente al refresco que las hermandades ofrecen a los hermanos y que consiste en la entrega de raciones de pan, vino y queso previa presentación del

se encargan de los cantos, limosnas, vestidos, etc. - sino también en el propio ritual. En San Sebastián son ellas las que, en su mayor parte, portan las andas del santo. En San Isidro llevan una imagen propia, femenina, su santa. Además, la bifurcación de la procesión por el «callejón de las mujeres» es altamente significativa. En relación a Santa Bárbara hemos oído decir que era una hermandad más de mujeres que de hombres. Asimismo, en 1982 en las tres subastas de varas y rosquillas fueron las mujeres las que más pujaron. El estudio de los papeles femeninos en las cofradias de Torrelaguna sería, no cabe duda, motivo suficiente para otra investigación. 
recibo del pago de la cuota anual. Tradicionalmente se reunían los hermanos en casa del alcalde para celebrar en confraternidad un ágape, pero hace bastantes años que éste no se celebra ${ }^{17}$. En 1982 lo hizo la de San Sebastián en los alrededores de la ermita, después de dar la ración, al igual que San Isidro que lo celebró en un Mesón-molino de uno de los hermanos. Todo ello en el intento de recuperar el espíritu de confraternidad y comensalidad que el ágape suponía. Santa Bárbara no lo celebra, limitándose exclusivamente al reparto de las raciones.

La fiesta finaliza con la procesión por la tarde para devolver el santo a la ermita. La procesión de San Sebastián y Santa Bárbara se inicia después de haberse celebrado una misa, sacando las imágenes las mismas personas que las metieron el día anterior. Se hace el recorrido a la inversa con los mismos alardes simbólicos (vivas, cohetes, etc.). Al llegar a la ermita se vuelven a subastar las varas y las rosquillas que quedaron del día anterior y después el cetro, introduciendo la imagen en la ermita y acabando la fiesta hasta el año siguiente.

Tradicionalmente ha existido una manifiesta oposición o "picajeo» entre las distintas hermandades grupales. Así, a los de San Sebastián se les recrimina el que lleven al santo medio desnudo, como si la hermandad no tuviera dinero para taparle, siendo, además, del Arrabal. A San Isidro, «el polainero», junto a Santa Bárbara se les achaca que estén en casa prestada. Asimismo, a los de San Isidro se les imputa una cierta negligencia por haber dejado caer la ermita de Santa María de la Cabeza, esposa del santo. Cotidianamente estos "piques» se manifiestan tanto en los centros escolares como en la competencia por el lucimiento de la fiesta y procesión.

La fiesta de la cofradía patronal se desarrolla con un esquema no demasiado diferenciado respecto al resto de las hermandades. Se celebra una novena, vísperas con procesión de la imagen y al día siguiente misa solemne y procesión de vuelta a la ermita. En la novena, las mujeres, los niños y personas con promesas son los principales asistentes. Es función de las camareras de la Virgen el organizar el aparato religioso, los cánticos litúrgicos, recogida de limosnas, vestidos de la Virgen, etc. Antaño durante la novena se rezaba el rosario en la ermita y se hacía

17 En San Sebastián el refresco lo pagaba la hermandad; sin embargo, el dinero era adelantado por el alcalde. Existía un presupuesto calculado por ésta para los gastos previsibles, pero si el alcalde sobrepasaba dicho presupuesto lo ponía de su propio peculio. En Santa Bárbara era el alcalde el que corría con los gastos del refresco, hasta que en 1884 se decide, mediante junta, dar una ayuda para sufragar dichos gastos. 
exposición del Santísimo; hoy se celebra una misa rezando una salve al finalizar.

En la víspera, por la tarde, comienza la procesión desde la ermita a la iglesia parroquial. Las varas de la Virgen antiguamente eran portadas por aquellos que, de manera informal, pujaban lanzando limosnas; aquel que más daba, sacaba la imagen. Este año estrenaron una carroza llevada por personas, hermanos o no, que lo tenían ofrecido.

Abriendo la comitiva va la banda de música. La Virgen se sitúa en el medio de la procesión y detrás de ella el párroco revestido -es la única celebración de hermandad a la que asiste a título oficial- y más atrás la corporación municipal que ese año asistió sin representación oficial. El hermano mayor o presidente porta el cetro sin ocupar un lugar determinado, sino que se encarga de organizar la comitiva. El resto de la Junta va repartida entre la parte delantera y posterior de la carroza. A la procesión asisten, además de la práctica totalidad del pueblo, devotos de la imagen venidos de fuera, muchos de ellos descalzos. Al tiempo se van lanzando cohetes. El itinerario es el mismo que realiza Santa Bárbara; la Puerta del Sol sigue significando el máximo esplendor de la procesión. A la puerta de la iglesia, una vez llegada la comitiva, se queman tres árboles de fuegos artificiales, se subastan las varas que alcanzan cotas extraordinariamente altas en relación a las otras hermandades y que habitualmente han sido ofrecidas por promesa y, una vez dentro, se canta la salve. Al día siguiente hay misa solemne concelebrada, con un orador especialmente traído para la fiesta. La procesión de la tarde se hace igual que la del día anterior, pero en sentido inverso. En la puerta de la ermita se vuelven a pujar las varas y se acaba introduciendo la imagen; al final se canta la salve.

\section{CONCLUSIONES}

Después de los datos ofrecidos podemos aventurar algunas conclusiones provisionales acerca de las hipótesis planteadas. Por una parte, parece claro que los tipos de hermandades grupales siguen actualmente desempeñando las funciones de prestar unos servicios netamente grupales, como la ayuda para el entierro y la manifestación ritual de pertenencia sectorial a través de la fiesta. La hermandad patronal aparece como aglutinante de las restantes y representando la devoción y la identidad común. La desaparición de los servicios de entierro marca un hito importante, a partir del cual se producirá la transición desde las funciones 
que expresaban la grupalidad, aunque ésta se hiciera extensiva a todo el pueblo, a las funciones de expresión comunal donde la estructura social de la comunidad aparece reflejada a través del ritual simbólico. Sin embargo, desconocemos las causas por las que se dejan de manifestar ritualmente las funciones de enterramiento. No obstante, estas funciones están reflejadas hoy, en el plano simbólico, por esa mínima aportación crematística que ningún hermano exige.

Respecto a la identificación de las hermandades grupales con la parroquia, diremos que las tres hermandades realizan el ritual procesional completo desde sus domicilios particulares, representando un sector social a la parroquia, asumiendo ésta la representación de la comunidad íntegra, cohesionada, pero ritualizada en la manifestación de sus partes. Estamos ante la reafirmación de los tres segmentos sociales significados en cada una de las hermandades que, a través de sus fiestas y procesiones, reproducen el esquema social existente, pero simbolizando, pese a todo, la unidad como pueblo al tener las tres un domicilio de pertenencia común: la parroquia. El paso por la Puerta del Sol donde el control y la crítica social ejercen su mayor poder, se contrarresta con los alardes de afirmación de identidad a través de los vivas y el estruendo de los cohetes. La cuantía obtenida por las pujas sirve como indicador de devocionalidad y fuerza de la expresión de identidad. El toque de campanas a la llegada de los santos viene a simbolizar la pertenencia de las partes individualizedas en un todo común.

La identificación de toda la comunidad con la hermandad comunal viene claramente expresada en la no presencia, ni formal ni simbólica, de las hermandades grupales. Se diluyen las identidades y pertenencias a grupos sociales en la reafirmación de la identidad colectiva a través del culto de la Virgen de la Soledad. Es significativo el hecho de que la Virgen de la Soledad aglutine, a través de su aparato ritual, a toda la comunidad llevándola a su ermita. Todo el pueblo se traslada a las afueras de la villa. Posteriormente, y en procesión, la hermandad -en representación de esa identidad colectiva - los integra de nuevo en la parroquia, señalando a ésta como símbolo de coherencia en tanto comunidad.

Toda esta "integración" de las hermandades grupales en la comunal puede obedecer a la fuerte estructura y organización de la hermandad de la Soledad. El control eclesiástico primero y la posterior reestructuración más jerarquizada aún por parte de los propios hermanos, hacen que sea la hermandad patronal la que diluya las tensiones y oposiciones intergrupales hacia una cohesión ideal, pero no real, de la propia comunidad. En este caso podríamos decir que la negación simbólica de la 
realidad social que se produce en las hermandades comunales, tal como sostiene Isidoro Moreno, en nuestro caso puede ser válida.

\author{
Miguel MARIA LÓPEZ COIRA \\ Universidad Complutense \\ Pilar Romero DE TEjada \\ Museo Nacional de Etnología
}

Los autores de este trabajo -utilizando como referencia teórica el modelo tipológico de hermandades propuesto por I. Moreno para el área andaluza - abordan la plausible validación de dicho modelo en una población rural de la Comunidad Autónoma de Madrid, mostrando el aparato formal y la expresión ritual de las diferentes hermandades en estudio. Los mecanismos de integración, así como la articulación de una estructura social segmentaria, quedan plasmados a través de un pormenorizado análisis de los niveles diferenciales de identificación social con la comunidad. Más claramente: si las hermandades grupales operan como aglutinantes sectoriales de la comunidad - con sus particulares mecanismos de identidad-, la hermandad patronal diluye las identidades y pertenencias a grupos sociales en la reafirmación de la identidad colectiva, a través del culto a la Virgen de la Soledad.

The authors of this work - using as a theoretical orientation the typologic model of confraternities proposed by I. Moreno, towards the area of Andalucía - tackle the plausible validation of such model in a rural village in the Comunidad Autónoma de Madrid, showing the formal system and ritual expressions of the different confraternities studied. The mechanisms of integration, as well as the articulation of a segmentary social structure, are shaped through a detailed analysis of a differential levels of social identification within the community. To explain it more clear: If the grupal confraternities work as sectorial aglutinants of the community - with their particular mechanisms of identity - the patronal confraternity disolves the identities and memberships of social groups in the reafirmation of the colective identity, through the cult towards Virgen de la Soledad. 